\title{
AVALIAÇÃO QUÍMICA E ACEITAÇÃO DA MERENDA ESCOLAR DE UMA ESCOLA ESTADUAL DE LAVRAS-MG ${ }^{1}$
}

\author{
Chemical evaluation and acceptance of meals offered by a public school in Lavras-MG
}

Eliete Fernandes Flávio², Maria de Fátima Píccolo Barcelos ${ }^{3}$, Andrelisa Lina de Lima ${ }^{4}$

\begin{abstract}
RESUMO
Com o presente estudo, objetivou-se analisar numa Escola Estadual de Lavras-MG a composição química e realizar pesquisa de aceitação sobre a merenda escolar, verificando se as mesmas atendiam às metas de recomendações nutricionais propostas pelo Programa Nacional de Alimentação Escolar (PNAE). Foram coletadas amostras da merenda escolar durante o segundo semestre de 2001, para a análise da composição química. A pesquisa de opinião foi realizada mediante questionários durante o mesmo período. Os valores de adequação em relação às metas do PNAE foram de $72,2 \% \pm 2,75$ para a proteína e $48,48 \pm 22,57$ para a energia. Em relação aos minerais, observaram-se $58 \%, 78 \%, 116 \%, 44 \%, 56 \%, 35 \%, 132 \%$ e $48 \%$ para $\mathrm{Ca}, \mathrm{Fe}, \mathrm{Zn}, \mathrm{Mg}, \mathrm{P}, \mathrm{Mn}, \mathrm{Cu}$ e K, respectivamente. As merendas que tinham como ingrediente básico o arroz apresentaram melhores índices de aceitação na pesquisa de opinião sobre a alimentação escolar.
\end{abstract}

Termos para indexação: Avaliação química, merenda escolar, aceitação.

\section{ABSTRACT}

The present study was intended to determine the chemical composition and acceptance of the lunch offered to the elementary school students of public school in Lavras-MG, and to verify if they meet the objectives of the School Feeding National Program. Samples were collected over the second semester of 2001, for chemical composition analyses. The values of adequability in relation to the goals of the Program were $72.2 \% \pm 2.75$ for protein and $48.48 \% \pm 22.57$ for energy. In relation to the minerals, values $58 \%, 78 \%, 116 \%, 44 \%, 56 \%, 35 \%, 132 \%$ and $48 \%$, for $\mathrm{Ca}, \mathrm{Fe}, \mathrm{Zn}, \mathrm{Mg}, \mathrm{P}, \mathrm{Mn}, \mathrm{Cu}$ and $\mathrm{K}$, respectively, were noticed. The school lunches which had a staple rice presented better acceptance indices.

Index terms: Chemical evaluation, school meal, acceptance.

(Recebido para publicação em 2 de setembro de 2002 e aprovado em 28 de novembro de 2002)

\section{INTRODUÇÃO}

O Programa Nacional de Alimentação Escolar (PNAE) é reconhecido pela United Nations Children's Found (UNICEF) como o maior projeto de alimentação do mundo. É o mais antigo programa social do Governo Federal Brasileiro, na área da Educação, atendendo durante os 200 dias letivos a 37 milhões de crianças e adolescentes por dia, correspondendo a $21 \%$ da população brasileira (FNDE, 2002).

Os recursos financeiros desse programa têm caráter suplementar e se destinam à aquisição de gêneros alimentícios. Após várias experiências de gestão centralizada e descentralizada, o programa adquiriu nova face em 1999, caracterizada, principalmente, pela transferência automática dos recursos financeiros e pela criação do Conselho de Alimentação Escolar, que en- volve a participação de representantes da comunidade, dos professores, dos pais de alunos e dos poderes Executivo e Legislativo (SARI, 2002). A direção das escolas públicas planeja o cardápio de acordo com a verba disponível, que é repassada com base no censo escolar do ano anterior e é orientada para dar preferência aos alimentos regionais, possibilitando, assim, uma maior aceitação da merenda, bem como maior incremento na renda local pela produção de alimentos regionais, e o valor repassado para cada estudante é de $\mathrm{R} \$ 0,13$ (treze centavos de reais)/dia, ou seja, o equivalente atualmente a \$ 0,04 (quatro décimos de dólar)/dia.

A merenda escolar representa um atrativo para a freqüência de considerada porcentagem de alunos matriculados nas escolas públicas, consistindo numa atividade integrada ao ensino (OLIVEIRA, 1997). O PNAE ganha uma dimensão social maior, à medida que, em

\footnotetext{
1. Parte da dissertação apresentada àUniversidade Federal de Lavras/UFLA - Caixa Postal 37 - 37200-000 - Lavras, MG, pela primeira autora para obtenção do título de Mestrado em Ciência dos Alimentos.

2. Nutricionista do Hospital Universitário da Universidade Estadual de Montes Claros/UNIMONTES, doutoranda do Curso de Ciência dos Alimentos da UFLA, eflavio@ufla.br

3. Dra. em Ciência da Nutrição, Professora Adjunta do Departamento de Ciência dos Alimentos da UFLA.

4. Acadêmica do curso de Agronomia da UFLA.
} 
face da pobreza de significativas parcelas da população brasileira, cresce o número de crianças que vão à escola em jejum e/ou que se alimentam em casa de maneira inadequada. Para muitos alunos das escolas brasileiras, a merenda é sua única refeição diária (ABREU, 1995; FNDE, 2002).

O cardápio da merenda escolar, sob responsabilidade das entidades executoras, deve ser programado de modo a suprir, no mínimo, $15 \%$ das necessidades nutricionais diárias dos alunos beneficiados. Uma recomendação, FNDE (2001), estabelece como principal meta do PNAE a garantia de que o aluno receba por refeição, em média, 350 kcal e 9 gramas de proteína, levando em consideração a ampla faixa etária de atendimento do programa (crianças pré-escolar até adolescentes). Essa proposta (15\% das necessidades nutricionais) do PNAE é baseada na Recommended Dietary Allowances (NRC, 1989), sendo também as mesmas recomendações referidas na Portaria $n^{\circ} 33$ da Agência Nacional de Vigilância Nacional (ANVISA, 2003). Portanto, o cardápio deverá ser programado de modo a fornecer refeições saborosas e adequadas, atendendo a $15 \%$ das necessidades nutricionais (BRASIL, 2001). Em avaliação recente dos programas sociais brasileiros, Marinho et al. (2002) concluíram que o PNAE têm levado à melhoria dos indicadores nutricionais dos alunos e à acentuada redução da evasão escolar.

A importância da alimentação para a criança em idade escolar reside no fato de ser uma fase de crescimento lento, porém, constante, ao passo que, para o adolescente, ocorre crescimento intenso. Em virtude dessas diferenças, as exigências nutricionais devem ser atendidas em todos os parâmetros (energéticos, protéicos, lipídicos, vitamínicos, minerais e de fibra). Muitas situações podem afetar o estado nutricional do escolar e adolescente, destacando-se ingestões inadequadas, pobreza, doenças nutricionais, fatores psicossociais e modo de vida (JACOBSON, 1998).

A aceitação de um alimento pelo aluno é o principal fator para determinar a qualidade do serviço prestado pelas escolas, no tocante ao fornecimento da merenda escolar. Para averiguar a aceitação de determinado alimento, a pesquisa de preferência e aceitação da merenda escolar é um instrumento fundamental, pois é de fácil execução e permite verificar a preferência média dos alimentos oferecidos (CALIL e AGUIAR, 1999).

Diante do exposto, objetivou-se com este trabalho analisar numa Escola Estadual de Lavras-MG a composição química e realizar a pesquisa sobre a aceitação da merenda escolar, verificando se elas atendiam às metas de recomendações nutricionais propostas pelo Programa Nacional de Alimentação Escolar.

\section{MATERIAL E MÉTODOS}

Este trabalho foi realizado pelo Departamento de Ciência dos Alimentos (DCA) da Universidade Federal de Lavras, que constou de um estudo da merenda escolar durante o período de agosto a dezembro de 2001, servida aos alunos do Ensino Fundamental (EF) de uma Escola Estadual do município de Lavras-MG.

\section{Amostra}

As amostras da merenda escolar oferecidas diariamente aos alunos do $\mathrm{EF}$ foram coletadas numa das sete escolas estaduais do município de Lavras-MG. O cardápio da merenda escolar estava estruturado com as seguintes preparações: sopa de macarrão com carne bovina e legumes, macarronada com carne bovina moída, arroz-doce, arroz temperado com carne bovina, tutu de feijão com ovos e couve, sopa de canjiquinha com carne bovina e sopa de farinha de milho com ovos. Na Tabela 1 é apresentado o per capta da porção diária oferecida. A escola avaliada situa-se na região sul da cidade de Lavras-MG e tinha matriculados em torno de 900 alunos no Ensino Fundamental e Médio, sendo 622 alunos no Ensino Fundamental, que têm direito à merenda escolar, conforme previsto no PNAE. O Ensino Fundamental é subdividido em três ciclos: básico $\left(1^{\circ}, 2^{\circ}\right.$ e $3^{\circ}$ ano), intermediário $\left(1^{\circ}, 2^{\circ}\right.$ e $3^{\circ}$ ano) e avançado ( $1^{\circ}$ e $2^{\circ}$ ano), conforme LDB 9394/96 (MINAS GERAIS, 2000); portanto, o Ensino Fundamental engloba os primeiros oito anos de estudo após o Pré-escolar.

\section{Análises químicas da merenda escolar}

Realizaram-se análises físico-químicas e químicas das merendas. Foram coletadas amostras da merenda escolar oferecida pela escola, durante a realização desse estudo, totalizando 59 coletas. Os dias de coleta das amostras foram aleatorizados, bem como a própria coleta, a qual foi realizada na fila de alunos na hora da distribuição diária da merenda pelas cantineiras. Era solicitado aleatoriamente a três alunos da fila que repassassem a sua merenda para a pesquisadora. Após a coleta das três porções da merenda em recipientes previamente pesados, elas foram conduzidas para o laboratório de Bioquímica Nutricional/ DCA, para serem pesadas e analisadas quimicamente. 
Foram determinados: umidade, cinza, extrato etéreo, nitrogênio total, fibra total e fração nifext (calculada por diferença dos demais componentes e considerada como valor de carboidratos) das 59 amostras coletadas. Os métodos utilizados foram os propostos pela AOAC (1990), com exceção da fração fibra, que foi determinada segundo o método gravimétrico, após digestão em meio ácido, conforme Kamer e Ginkel (1952). A proteína foi determinada pelo método semi-micro Kjeldahl, multiplicando-se o nitrogênio pelo fator 6,25. A determinação do extrato etéreo foi realizada pela extração com éter etílico, em aparelho tipo Soxhlet. Após a extração e remoção do solvente, determinou-se, gravimetricamente, a quantidade de lipídios presente nas amostras. O teor de cinzas foi determinado pela calcinação da amostra, em mufla a $550^{\circ} \mathrm{C}$, até obtenção de cinzas claras. Realizaram-se análises dos seguintes minerais: $\mathrm{P}, \mathrm{K}, \mathrm{Ca}$, $\mathrm{Mg}, \mathrm{S}, \mathrm{Cu}, \mathrm{Mn}, \mathrm{Zn}$ e Fe, conforme Sarruge e Haag (1974) e Malavolta et al. (1989). Os extratos foram obtidos por digestão nitroperclórica. O P e o S foram determinados por colorimetria, segundo método da AOAC (1990); Ca, Mg, Cu, Fe, Mn e Zn, por espectrofotometria de absorção atômica e K, por fotometria de chama.

\section{Pesquisa de opinião sobre a aceitação da me- renda escolar}

A pesquisa de opinião sobre a aceitação da merenda escolar foi realizada conforme metodologia descrita por Calil e Aguiar (1999), durante o período da realização do estudo em questão, com a aplicação de questionários com todos os alunos matriculados no Ensino Fundamental. A "pesquisa sobre a alimentação escolar" baseia-se na verificação da opinião dos alunos quanto à preferência e aceitação pelos alimentos ofertados na merenda escolar.

Pelos questionários que foram aplicados aos alunos do EF, pôde-se verificar a opinião sobre a qualidade da merenda escolar (qualidade do serviço oferecido ao aluno), obter informações das merendas preferidas (cardápios mais ou menos preferidos), conhecer os hábitos dos alunos quanto ao número de vezes que merendavam/semana (freqüência do ato de merendar na escola), quais preparações preferiam repetir (cardápios que os alunos mais repetiam ou não), se a alimentação consumida era exclusivamente da escola (frequiência do ato de trazer alimentos de suas casas). Essas opiniões foram tabuladas e registradas em termos percentuais. Os questionários foram respondidos por 598 alunos, representando $96 \%$ do total de alunos matriculados no segundo semestre de 2001.

\section{RESULTADOS E DISCUSSÃO}

\section{Composição química da merenda escolar}

Observa-se na Tabela 1, na qual são apresentadas as médias da composição química das 59 amostras, g/100 g e g/porção total diária, que o teor médio de proteína por porção oferecida pela escola é $6,5 \mathrm{~g} / \mathrm{dia}$, enquanto o teor de gordura e fração glicídica é de 3,5 g/dia e 28,92 g/dia, respectivamente. A distribuição do valor calórico total (VCT) desses teores de nutrientes por porção média é de 15,02\%, $18,20 \%$ e $66,78 \%$ para a proteína, gordura e fração glicídica, respectivamente. Mahan e Escott-Stump (1998) recomendam que a proporção de energia para a faixa etária do escolar e do adolescente seja de 10 a $15 \%$ de proteína, 25 a $35 \%$ de lipídio e 50 a $60 \%$ de carboidrato. No presente estudo, registraram-se adequação para a proteína, uma proporção maior para a fração glicídica e menor para os lipídios, de acordo com essa recomendação.

O valor obtido para a proteína (Tabela 1) é muito importante diante dos objetivos do PNAE, pois esse órgão recomenda que seja fornecido por dia, na merenda escolar, $9 \mathrm{~g}$ de proteína (FNDE, 2001). O teor verificado no presente estudo representa 72,2 $\pm 2,75$ de adequação em relação à recomendação do PNAE, baseada na NRC (1989), conforme relatado anteriormente. Quanto ao valor calórico da porção (kcal/porção) da merenda escolar analisada, observou-se que a média foi de 170,03 kcal/dia, representando adequação de 48,58\% \pm 22,57, em relação à recomendação do PNAE de fornecer $350 \mathrm{kcal} / \mathrm{dia}$ (FNDE, 2001). Salay e Carvalho (1995), ao avaliarem o programa de merenda escolar em escolas estaduais do município de Campinas, encontraram uma adequação protéica de $52,7 \% \pm 17,2$, para a energia de 48,6 \pm $17,3 \%$. 
TABELA 1 - Média ${ }^{1}$ geral da composição centesimal e da composição da porção da merenda escolar em g/100g e g/porção diária oferecidas respectivamente aos alunos do Ensino Fundamental de uma Escola Estadual do município de Lavras-MG, durante segundo semestre de 2001.

\begin{tabular}{lccccccc}
\hline \multirow{2}{*}{ Tamanho da Amostra } & \multicolumn{7}{c}{ Composição química } \\
\cline { 2 - 7 } & Umidade & E. Etéreo & Cinza & Fibra & Proteína $^{\mathbf{2}}$ & E.N.N $^{\mathbf{3}}$ & Total \\
\hline $\begin{array}{l}\text { Composição centesimal } \\
\text { (g/100g) }\end{array}$ & 78,05 & 1,66 & 1,21 & 0,22 & 3,51 & 15,35 & 100,00 \\
$\begin{array}{l}\text { Porção diária } \\
\text { (g/ total da porção) }\end{array}$ & 148,05 & 3,15 & 2,30 & 0,40 & 6,50 & 28,92 & 189,32 \\
\hline DP da porção diária & 36.89 & 1,77 & 0,97 & 0,44 & 2,75 & 14,89 & 39,83 \\
\hline
\end{tabular}

${ }^{1}$ Média das 59 amostras coletadas durante o período de agosto-dezembro/2001

${ }^{2} \mathrm{~N} \times 6,25$

${ }^{3}$ E.N.N= extrato não-nitrogenado (calculado por diferença)

\section{Composição mineral da merenda escolar}

A caracterização da fração cinza de um alimento em cada um dos seus minerais constituintes (Tabela 2) é de fundamental importância em virtude de funções desempenhadas no metabolismo pelo mineral. As recomendações, baseadas na NRC (1989), e valores médios diários oferecidos na merenda escolar, bem como o percentual de adequação dos macrominerais ( $\mathrm{Na}, \mathrm{P}$, $\mathrm{K}, \mathrm{Ca}, \mathrm{Mg}$ e $\mathrm{S})$ e dos microminerais $(\mathrm{Cu}, \mathrm{Mn}, \mathrm{Zn}$ e $\mathrm{Fe})$ são apresentados na Tabela 2. Os macrominerais (Ca, Mg, Na, K, P, S e Cl) são necessários em quantidades maiores que $100 \mathrm{mg} / \mathrm{dia}$, enquanto os microminerais ou elementos traços (Fe, I, Cu, $\mathrm{Zn}, \mathrm{Co}$, Mo e Cr) são necessários em quantidades menores que $100 \mathrm{mg} / \mathrm{dia}$.

O teor médio de cálcio (Tabela 2) oferecido pela escola foi de $98 \mathrm{mg} /$ dia; portanto, apresentando adequação de $58,3 \%$, em relação à recomendação do PNAE, baseada na NRC (1989). Em relação ao teor de ferro, verificou-se que o valor médio foi de $1,5 \mathrm{mg}$ de $\mathrm{Fe} /$ porção diária; portanto, a adequação para essa recomendação foi de $78,1 \%$. No estudo da dieta de préescolares de baixa renda, Rivera e Rivera (1986) verificaram que o valor médio obtido para o teor de ferro foi de $93 \%$ da adequação e para o cálcio foi de $43 \%$, comparando-a com os requerimentos da FAO/OMS. Silva (1995), estudando a merenda escolar de escolas públicas da cidade de Piracicaba, verificou que em termos médios a adequação de cálcio revelou-se próxima de $40 \%$. É conveniente ressaltar que, de maneira geral, os vegetais são ricos em ferro, embora a presença de outros compostos, como fibras alimentares, fitatos e oxalatos, tornem o ferro menos absorvível pelo intestino humano, da mesma maneira que ocorre com o cálcio (CUNHA e CUNHA, 2000). Por outro lado, com o consumo de frutas cítricas e de outros alimentos ricos em vitamina $\mathrm{C}$, pode-se elevar a biodisponibilidade do ferro.

Quanto ao teor de zinco (Tabela 2), verificou-se que o valor médio do teor de $\mathrm{Zn}$ oferecido na merenda foi de 2,2 mg/porção diária, e que a recomendação média, conforme NRC (1989) para os alunos da escola em estudo, seria de $12,2 \mathrm{mg} /$ dia. Portanto, a adequação observada para essa recomendação foi de $116,1 \%$. Esse valor de $\mathrm{Zn}$ acima da recomendação não representa um risco para a saúde, pois a suplementação excessiva de zinco geralmente promove aumento da excreção do mineral nas fezes, e está abaixo do limite da toxicidade (CUNHA e CUNHA, 2000).

O teor médio de magnésio oferecido na merenda escolar foi de $19 \mathrm{mg} /$ porção diária (Tabela 2). A recomendação nutricional média de $\mathrm{Mg}$ para o públicoalvo do programa, faixa etária de 7-18 anos, na escola em questão é de 284 mg/dia, segundo a NRC (1989). A adequação observada para essa recomendação foi de $44,2 \%$. Esse valor baixo é preocupante, em virtude das funções desempenhadas no organismo humano por esse mineral. O Mg desempenha papel fundamental em uma série de reações, incluindo metabolismo dos carboidratos, lipídios, proteínas e ácidos nucléicos (DUTRA-DEOLIVEIRA e MARCHINI, 2000). 
TABELA 2 - Valores médios dos teores dos elementos minerais nas porções diária (mg/dia) da merenda escolar, valor médio para suprir as recomendações proposta pelo PNAE, \% de adequação da recomendação do PNAE oferecida aos alunos do Ensino Fundamental de uma escola estadual do município de Lavras-MG, durante o segundo semestre de 2001.

\begin{tabular}{|c|c|c|c|c|c|c|c|c|c|}
\hline \multirow{2}{*}{ Valores médios } & \multicolumn{5}{|c|}{ Macrominerais (mg/dia) } & \multicolumn{4}{|c|}{ Microminerais (mg/dia) } \\
\hline & $\mathbf{P}$ & $\mathbf{K}$ & $\mathbf{C a}$ & Mg & $\mathbf{S}$ & $\mathbf{C u}$ & Mn & $\mathbf{Z n}$ & $\mathbf{F e}$ \\
\hline $\begin{array}{l}\text { Teor médio/dia } \\
\text { oferecido ao aluno }^{1}\end{array}$ & 95,4 & 130 & 98 & 19 & 50,4 & 0,350 & 0,159 & 2,23 & 1,50 \\
\hline $\begin{array}{l}\text { Recomendação média } \\
\text { para os alunos do } \mathrm{EF}^{2}\end{array}$ & 1120 & 1800 & 1120 & 284 & $*$ & $1,25-2,25$ & $2,0-4,0$ & 12,8 & 12,8 \\
\hline $\begin{array}{l}\text { Proposta do PNAE } \\
(15 \% \text { recomendação) })^{3}\end{array}$ & 168 & 270 & 168 & 43 & $*$ & $0,19-0,34$ & $0,3-0,6$ & 1,92 & 1,92 \\
\hline $\begin{array}{l}\text { Adequação }(\%) \text { da } \\
\text { recomendação do } \\
\text { PNAE }^{4}\end{array}$ & 56,8 & 48,1 & 58,3 & 44,2 & $*$ & 132,1 & 35,3 & 116,1 & 78,1 \\
\hline
\end{tabular}

\footnotetext{
${ }^{1}$ Média geral das 59 amostras da merenda escolar analisada

${ }^{2}$ Recomendação média de minerais para as faixas etárias dos alunos do EF, segundo a NRC (1989)

${ }^{3} 15 \%$ das médias das recomendações nutricionais para as faixas etárias de 7-10, 11-14, 15-18, conforme NRC (1989)

${ }^{4} \%$ de adequação da recomendação nutricional oferecida pela escola estadual em relação à proposta de recomendação do PNAE
}

*Não tem recomendação específica para esse nutriente; as suas necessidades são supridas quando tem-se um aporte adequado de proteínas (aminoácidos contendo enxofre) na dieta diária (MAHAN e SCOTT-STUMP, 1998).

Em relação ao fósforo, nota-se, na Tabela 2, que o valor médio das amostras estudadas é de 95 mg/porção diária. A adequação, conforme NRC (1989), observada para essa recomendação foi de 56,8\%. Em um estudo da dieta de pré-escolares de baixa renda, Rivera e Rivera (1986) verificaram que o valor obtido para o teor de fósforo foi de $134 \%$, comparando-o com os requerimentos da FAO/OMS. Quanto ao manganês, observou-se (Tabela 2) que o valor médio oferecido nas merendas escolares aos alunos foi de $0,159 \mathrm{mg} / \mathrm{dia}$. A adequação para a recomendação do PNAE, baseada na NRC (1989), para esse mineral foi de $35,3 \%$, portanto, muito baixa em função dos tipos de preparações oferecidas na merenda escolar. Nota-se, ainda, que o teor médio de enxofre (Tabela 2) oferecido na merenda escolar foi de $50,43 \mathrm{mg} /$ dia. Não há recomendação até o presente momento para esse nutriente, conforme NRC (1989). Segundo Mahan e Escott-Stump (1998), as necessidades de enxofre são supridas pela ingestão adequada de proteínas. Como a adequação em relação às recomendações da NRC (1989) para a proteína foi de $48,1 \%$ (Tabela 1), infere-se que a ingestão desse mineral não tenha preenchido as recomendações diárias.

Em relação ao cobre, nota-se (Tabela 2) que o valor médio oferecido nas merendas escolares aos alunos foi de $0,350 \mathrm{mg} / \mathrm{dia}$. $\mathrm{O} \mathrm{Cu}$ é componente de diversas enzimas e está envolvido no desenvolvimento e manutenção da integridade cardiovascular e esquelética, na estrutura e função do sistema nervoso central e na função eritropoiética (MAHAN e ESCOTT-STUMP, 1998). A adequação para a recomendação, conforme a NRC (1989), foi de 132,1\%, e mesmo estando acima da proposta, encontra-se dentro dos limites da tolerância.

Pesquisa de opinião sobre a aceitação da merenda escolar

A maior parte dos alunos entrevistados (72\%) relataram que tinham o hábito de consumir a merenda oferecida pela escola, enquanto $28 \%$ informaram que 
não tinham. Na escola onde foi efetuado o estudo, não havia cantinas ou lanchonetes; portanto, durante o período de aula, o aluno tinha como opção ingerir a merenda oferecida pela escola ou algum alimento trazido de casa.

Sobre a freqüência semanal do consumo da merenda escolar, observou-se que $25 \%$ alunos entrevistados responderam que consumiam a merenda oferecida pela escola diariamente; $11 \%$ consumiam quatro vezes/semana; $14 \%$ consumiam três vezes/semana; $19 \%$ consumiam duas vezes/semana e $15 \%$ só consumiam uma vez/semana, enquanto $16 \%$ dos entrevistados disseram que não consumiam a merenda oferecida pela escola; a maioria, ao ser questionada sobre os motivos para tal hábito, disse que não tinha fome no horário de distribuição da merenda.

Em relação ao hábito de trazer alimentos para a escola, verificou-se que apenas $32 \%$ dos alunos responderam positivamente a esse questionamento. Quando foram questionados com que freqüência traziam lanche de casa, foi verificado que $70 \%$ traziam só uma vez/semana. No entanto, a maioria $(68 \%)$ dos alunos entrevistados não traziam alimentos para a escola, ficando, portanto, com a opção de comer a merenda oferecida pela escola, pois conforme mencionado, na escola não havia cantinas ou lanchonetes.

Quanto ao hábito de repetir a merenda escolar, observou-se que $61 \%$ dos alunos responderam afirmativamente a esse questionamento. Após distribuir a merenda para todos os alunos que estavam na fila, quando havia sobras limpas, a cantineira repetia a merenda para os alunos que solicitavam. A quantidade repetida para cada aluno dependia do número de alunos que estavam na fila, bem como da quantidade de sobras. Esses dados concordam com os dados sobre a freqüência com que traziam lanches para a escola, pois $68 \%$ dos alunos disseram que não tinham o hábito de trazer lanche para a escola.

Ao analisar os dados sobre a preferência dos alunos em relação às merendas oferecidas pela escola, percebeu-se que o arroz temperado com carne moída, o arroz-doce e a macarronada com carne moída obtiveram os seguintes percentuais de escolha: $90 \%, 70 \%$ e $67 \%$, respectivamente. O cardápio da merenda escolar oferecido pela escola, no segundo semestre de 2001, estava estruturado com sete tipos de merenda: sopa de macarrão com carne e legumes; canjiquinha com carne e couve; macarronada com molho e carne moída; arrozdoce; sopa de farinha de milho com ovos e couve; arroz temperado com carne e tutu de feijão com ovos e couve.
A sopa de farinha de milho com ovos e couve foi a que obteve o menor percentual de escolha (27\%), seguida do tutu de feijão com ovos e couve (30\%). Esses percentuais devem-se ao fato de o aluno ter escolhido as preparações do seu agrado; portanto, houve alguns alunos que escolheram mais de uma formulação. É interessante associar os dados sobre o hábito de repetir a merenda com determinados cardápios que eram os preferidos pelos alunos, pois observou-se que dos $61 \%$ dos alunos que tinham o hábito de repetir a merenda escolar, $41 \%$ preferiam repetir o arroz temperado com carne e $15 \%$ dos alunos repetiam todas as merendas oferecidas pela escola. Ainda constatou-se que a merenda que obteve o segundo maior percentual de escolha como preferida, para ser repetida pelos alunos, foi o arroz-doce $(25 \%)$.

Em relação à qualidade do serviço de merenda escolar, observou-se que a maioria dos alunos entrevistados, ou seja, $76 \%$ opinaram que o serviço de merenda escolar está entre bom e ótimo, e $19 \%$ relataram que era ótimo e $16 \%$ muito bom. Só $21 \%$ dos alunos entrevistados classificaram como regular e apenas $3 \%$ como ruim. Com esses dados, confirmam-se os elevados índices de aceitação da merenda escolar. E, também, ilustram os relatos de Cardoso et al. (2002) e Marinho et al. (2002), que realizaram uma avaliação da eficiência dos programas sociais brasileiros e concluíram que o PNAE tem uma eficiência bastante elevada. Guimarães (2002) observou que a verba da merenda escolar está cumprindo sua função social. Seu objetivo de suprir parcialmente as necessidades nutricionais dos alunos, com oferta de, no mínimo, uma refeição diária rica em nutrientes, vem obtendo resultados, tanto na elevação dos níveis de rendimento escolar, quanto na introdução de novos hábitos alimentares, além, é claro, de atrair a criança à sala de aula, evitando a evasão escolar.

\section{CONCLUSÕES}

Baseado no estudo da merenda escolar e entre os parâmetros analisados, conclui-se que:

a) As merendas oferecidas na escola em estudo, no segundo semestre de 2001, não atenderam totalmente às metas propostas pelo PNAE quanto ao conteúdo protéico, valor calórico e teor de alguns minerais, baseadas nas recomendações da NRC (1989);

b) A aceitação da merenda escolar mostrou-se satisfatória, atendendo às metas do PNAE quanto ao aspecto sensorial, e os cardápios que possuíam o arroz como ingrediente básico apresentaram os maiores percentuais de aceitação; 
c) É necessário um acompanhamento efetivo de profissionais da área de alimentação e nutrição a cada semestre letivo nas escolas conveniadas com o PNAE, objetivando realizar as adequações pertinentes quanto ao planejamento de cardápios, buscando, assim, a adequação deles no tocante às necessidades nutricionais do público-alvo da merenda escolar.

\section{REFERÊNCIAS BIBLIOGRÁFICAS}

ABREU, M. Alimentação escolar: combate à desnutrição e ao fracasso escolar ou direito da criança e ato pedagógico? Em Aberto, Brasília, 1995. Disponível em: <http://www.inep.gov.br.>. Acesso em: 9 set. 2001.

AGÊNCIA NACIONAL DE VIGILÂNCIA SANITÁRIA. Portaria n. 33, de 13 de janeiro de 1998. Disponível em: <http://www.anvisa.gov.br/legis/portaria/33 98htm>. Acesso em: 10 jun. 2003.

ASSOCIATION OF OFFICIAL ANALYTICAL CHEMISTS. Official methods of analytical. 15. ed. Washington, 1990. v. 2.

BRASIL. Resolução n. 15, de 25 de agosto de 2000. Programa Nacional de Alimentação Escolar- PNAE. Disponível em: <http://www.fnde.gov.br/legislação/ pnae/htlm>. Acesso em: 25 abr. 2001.

CALIL, R.; AGUIAR , J. Nutrição e administração nos serviços de alimentação escolar. São Paulo: Marco Markovitchi, 1999. 80 p.

CARDOSO, L. C.; FAÇANHA, L. O.; MARINHO, A. Texto para discussão No 859/ IPEA. Avaliação de programas sociais (PNAE, PLANFOR, PROGER): eficiência relativa e esquemas de incentivo. Rio de Janeiro: IPEA, 2002. 44 p. Disponível em: <http://www.ipea.gov.br>. Acesso em: 1 mar. 2002.

CUNHA, D. F.; CUNHA, S. T. C. Microminerais. In: DUTRA-DE-OLIVEIRA, J. E.; MARCINI, J. S. Ciências nutricionais. São Paulo: Sarvier, 2000. cap. 9, p. 141-165.

DUTRA-DE-OLIVEIRA, J. E.; MARCINI, J. S. Macrominerais. In: Ciências nutricionais. São Paulo: Sarvier, 2000. cap. 8, p. 133-138.

FUNDO NACIONAL DE DESENVOLVIMENTO DO ENSINO. Merenda escolar. Disponível em: <http:// www.fnde.gov.br/>. Acesso em: 17 fev. 2001.
FUNDO NACIONAL DE DESENVOLVIMENTO DO ENSINO. Merenda escolar: você Sabia? 〈http://www. fnde.gov.br/vcsabia/vcsabia0002.html >. Acesso em: 17 fev. 2002.

GUIMARÃES, M. M. Opinião: o novo sabor da merenda escolar. Disponível em: <http://www.mec. gov.br/acs/jornalis/ar_diversos/5-d. shtm>. Acesso em: 25 maio 2002.

JACOBSON, M. S. Nutrição na adolescência. Anais NESTLÉ, São Paulo, v. 55, p. 24-33, 1998.

KAMER, J. H. van de; GINKEL, L. van. Rapid determition of crude fiber in cereais. Cereal Chemistry, Saint Paul, v. 29, n. 4, p. 239-251, July/Aug. 1952.

MAHAN, L. K.; ESCOTT-STUMP, S. Krause alimentos, nutrição e dietoterapia. Traduzido por A. Favano. 9. ed. São Paulo: Roca, 1998. 179 p. Título original: Krause's food, nutrition e diety therapy.

MALAVOLTA, E.; VITTI, G. C.; OLIVEIRA, S. A. Avaliação de estado nutricional de plantas. Piracicaba: Potafos, 1989. 201 p.

MARINHO, A.; CARDOSO, L.; FAÇANHA, L. O. IPEA avalia eficiência de programas sociais. Jornal do IPEA, Rio de Janeiro, ano 1, n. 4, p. 3, fev. 2002. Disponível em: 〈http://www.ipea.gov.br〉. Acesso em: 1 mar. 2002.

MINAS GERAIS. Resolução n. 006, de 20 de janeiro de 2000. Caderno-1. Diário do Executivo, Legislativo e Publicações de Terceiros, Belo Horizonte, 21 de Janeiro de 2000.

NATIONAL RESEARCH COUNCIL. Recommended dietary allowances. 10. ed. Washington: National Academic Science, 1989. 284 p.

OLIVEIRA, D. A. G. Avaliação química, nutricional e sensorial de uma mistura à base de farinhas de arroz, banana e mandioca enriquecida com outras fontes protéicas. 1997. 79 f. Dissertação (Mestrado em Ciência e Tecnologia de Alimentos) - Escola Superior de Agricultura Luiz de Queiroz, Piracicaba, 1997.

RIVERA, M. A. A.; RIVERA, F. A. C. Perfil nutricional da dieta de escolares e pré-escolares pertencentes à população de baixa renda. 1986. Disponível em: <http://bireme.br/>. Acesso em: 5 jul. 2001. 
SALAY, E.; CARVALHO, J. F. de. Avaliação do programa de merenda escolar do município de Campinas, Brasil. Archivos Latinoamericanos de Nutricion, Caracas, v. 45, n. 3, p. 167-171, jul./set. 1995.

SARI, M. T. PGM 2 Conselho de alimentação escolar. Disponível em: <http://www.tvebrasil.combr/salto/ cont/conttxt1.html.>. Acesso em: 2 maio 2002.
SARRUGE, J. R. R.; HAAG, H. P. Análise química em plantas. Piracicaba: ESALQ/USP, 1974. 56 p.

SILVA, M. V. da. Contribuição do programa de merenda escolar: ciclo básico: para as recomendações nutricionais de escolares. Archivos Latinoamericanos de Nutricion, Caracas, v. 45, n. 2, p. 103-110, abr./jun. 1995. 